\title{
Effect of nitrazepam and flurazepam on the ventilatory response to carbon dioxide
}

\author{
D. M. GEDDES, M I CHAEL RUDOLF, \\ and K. B. SA UNDERS \\ Department of Medicine, The Middlesex Hospital, London W1N 8 AA
}

\begin{abstract}
Geddes, D. M., Rudolf, M., and Saunders, K. B. (1976). Thorax, 31, 548-551. Effect of nitrazepam and flurazepam on the ventilatory response to carbon dioxide. Ventilatory response to $\mathrm{CO}_{2}$ was measured before and after two different benzodiazepine hypnotics in both chronic bronchitics and patients without chest disease. Flurazepam, but not nitrazepam, produced a significant decrease in $\mathrm{CO}_{2}$ sensitivity, although there was no significant change in $\mathrm{FEV}_{1}$ or mixed venous $\mathrm{PCO}_{2}$. This is the first unequivocal evidence of central depression of respiration by a benzodiazepine and may be the mechanism by which benzodiazepines cause deterioration in patients with respiratory failure.
\end{abstract}

It is generally accepted that any form of sedative may cause deterioration in a patient with respiratory failure. This has been attributed to depression of central respiratory drive, and impaired ventilatory response to carbon dioxide has been well demonstrated with both morphine and barbiturates (Weil et al., 1975; Gasser, Kaufman, and Bellville, 1975). Benzodiazepines have been reported to cause deterioration in patients with chronic respiratory failure during an acute exacerbation (Clark, Collins, and Tong, 1971), but the effect of these drugs on such patients when they are in a stable state is less well established and the mechanism of the respiratory depression is unknown. In one of the patients reported by Clark et al. (1971), administration of nitrazepam was followed by a severe worsening of respiratory failure although that patient had taken the same drug on previous occasions without ill-effect. It was suggested that acute pulmonary infection might increase the susceptibility to respiratory depression. There is, however, no good evidence that benzodiazepines are respiratory depressants in normal subjects or in patients with stable chronic respiratory disease.

We have therefore conducted a double-blind cross-over trial using nitrazepam, flurazepam, and placebo in patients with and without respiratory disease in order to investigate the effects of these drugs on the ventilatory response to $\mathrm{CO}_{2}$. In Britain, nitrazepam (Mogadon) is the most widely prescribed non-barbiturate hypnotic. Flurazepam
(Dalmane) is a more recently available benze diazepine which has theoretical advantages sinse more rapid recovery of skilled performance aftor equipotent doses of this drug and nitrazepam has been demonstrated (Borland and Nicholson, 1973)

\section{PATIENTS AND METHODS}

PATIENTS Twelve patients were studied. The pro cedure and purpose of the experiment were fuly explained to them, and informed consent was oftained. The study had been approved by the hospital's Clinical Investigation Panel. Six patients (4 male, 2 female, aged 49-68) hăd chronic bronchitis as defined by the Medicall Research Council (1965) with spirometric evidenge of fixed airways obstruction. All these patients had smoked 10 or more cigarettes per day for more than 10 years. Mixed venous carbon dioxide tension was normal in four and slightly raised two patients. The remaining six patients $(2$ mats 4 female, aged 17-69) had no evidence of respiristory disease and were in hospital for the investigs tion of other unrelated conditions.

METHODS Ventilatory response to $\mathrm{CO}_{2}$ wes measured using the rebreathing technique of Re (1967), and the result was expressed as the slope of the line obtained by performing least squargs regression analysis of the minute ventilation end-tidal $\mathrm{CO}_{2}$ tension, ignoring the first 30 secon $\$$ of breathing. The intercept of the slope at zero ventilation was also calculated. 
Forced expired volume in one second $\left(\mathrm{FEV}_{1}\right)$ was measured before each rebreathing procedure using a Vitalograph spirometer, and the best of three attempts was recorded. The mixed venous carbon dioxide tension $\left(\mathrm{P}_{\overline{\mathrm{V}}} \mathrm{CO}_{2}\right)$ was estimated before each rebreathing test according to the method of Campbell and Howell (1962).

PROTOCOL Each patient performed $\mathrm{FEV}_{1}, \mathrm{P}_{\overline{\mathrm{V}}} \mathrm{CO}_{2}$, and $\mathrm{CO}_{2}$ rebreathing tests at least twice before the trial in order to become familiar with the equipment. Measurements were made in the morning with the patient fasting. No drugs were given on the morning of the test, and all patients had taken no form of sedative or hypnotic during the two weeks before the test. $\mathrm{FEV}_{1}$ and rebreathing $\mathrm{P}_{\mathrm{V}} \mathrm{CO}_{2}$ were measured. The patient then rested for at least five minutes, after which the ventilatory response to $\mathrm{CO}_{2}$ was measured. A tablet was then given and observed to be swallowed. The patient rested for two hours without further drugs, coffee, tea or cigarettes, and the measurements were then repeated. Subsequently the measurements were repeated using the other tablets with intervals of at least 48 hours between experiments. The tablet order was randomized and doubleblind.

The tablets contained nitrazepam, $5 \mathrm{mg}$, flurazepam, $15 \mathrm{mg}$, or placebo.

Differences between pre- and post-drug values were analysed for significance using Student's $t$ test for paired data.

\section{RESULTS}

VENTILATORY RESPONSE TO $\mathrm{CO}_{2}$ The results are shown in Table I. There were no significant differences between the control values obtained before each of the three tablets was taken. Neither placebo nor nitrazepam produced any significant change in ventilatory response. However, after flurazepam $\mathrm{CO}_{2}$ sensitivity was significantly decreased $(P<0.02)$, and indeed no ventilatory response could be detected in two patients after taking this drug. No significant differences between the intercepts at zero ventilation were found.

The bronchitic group had a lower mean ventilatory response than the non-respiratory group, but there was no difference between the two groups in the effect of the drugs on $\mathrm{CO}_{2}$ responsiveness and they were therefore combined for statistical analysis.
T A B L E I

VENTILATORY RESPONSE TO $\mathrm{CO}_{2}$ EXPRESSED AS $1 \mathrm{~min}^{-1} \mathrm{kPa}^{-1}$

\begin{tabular}{|c|c|c|c|c|c|c|}
\hline \multirow{2}{*}{ Group } & \multicolumn{2}{|c|}{ Placebo } & \multicolumn{2}{|c|}{ Nitrazepam } & \multicolumn{2}{|c|}{ Flurazepam } \\
\hline & Pre & Post & Pre & Post & Pre & Post \\
\hline Bronchitic & $\begin{array}{r}8 \cdot 87 \\
1 \cdot 83 \\
3 \cdot 06 \\
2 \cdot 30 \\
5 \cdot 85 \\
16 \cdot 37\end{array}$ & $\begin{array}{r}10 \cdot 70 \\
3 \cdot 78 \\
2 \cdot 93 \\
2 \cdot 85 \\
6 \cdot 48 \\
12 \cdot 02\end{array}$ & $\begin{array}{r}11 \cdot 23 \\
3 \cdot 49 \\
3 \cdot 47 \\
\overline{5 \cdot 27} \\
12 \cdot 16\end{array}$ & $\begin{array}{r}11 \cdot 49 \\
2.17 \\
3.41 \\
\overline{5.79} \\
13.98\end{array}$ & $\begin{array}{r}9 \cdot 84 \\
3.05 \\
3 \cdot 46 \\
1 \cdot 61 \\
4 \cdot 34 \\
14 \cdot 00\end{array}$ & $\begin{array}{l}9 \cdot 08 \\
2 \cdot 57 \\
0 \\
0 \\
5 \cdot 78 \\
12 \cdot 61\end{array}$ \\
\hline Non-respiratory & $\begin{array}{r}13 \cdot 94 \\
14 \cdot 15 \\
8 \cdot 08 \\
7 \cdot 27 \\
7 \cdot 20 \\
12 \cdot 08\end{array}$ & $\begin{array}{r}10 \cdot 96 \\
12.88 \\
9 \cdot 01 \\
8.40 \\
7.49 \\
7 \cdot 73\end{array}$ & $\begin{array}{r}\overline{11 \cdot 88} \\
7.68 \\
5.42 \\
10.34 \\
13.62\end{array}$ & $\begin{array}{r}-\overline{5 \cdot 90} \\
10.58 \\
3 \cdot 42 \\
5 \cdot 20 \\
6 \cdot 14\end{array}$ & $\begin{array}{r}16 \cdot 22 \\
16 \cdot 47 \\
10 \cdot 64 \\
6 \cdot 53 \\
5 \cdot 75 \\
11 \cdot 18\end{array}$ & $\begin{array}{r}9.64 \\
13.64 \\
7.97 \\
3.45 \\
7.47 \\
8.08\end{array}$ \\
\hline $\begin{array}{l}\text { Mean } \\
\text { SEM }\end{array}$ & $\begin{array}{l}8 \cdot 42^{1} \\
1 \cdot 40\end{array}$ & $\begin{array}{l}7.94^{2} \\
1.00\end{array}$ & $\begin{array}{l}8 \cdot 46^{1} \\
1 \cdot 22\end{array}$ & $\begin{array}{l}7 \cdot 81^{2} \\
1 \cdot 53\end{array}$ & $\begin{array}{l}8 \cdot 59^{1} \\
1 \cdot 51\end{array}$ & $\begin{array}{l}6 \cdot 69^{3} \\
1 \cdot 28\end{array}$ \\
\hline
\end{tabular}

${ }^{1}$ No significant difference between pre-drug values.

${ }^{2}$ No significant difference between pre- and post-drug values. significant decrease in post-drug value $(P<0.02)$.

MIXED VENOUS $\mathrm{CO}_{2}$ AND FEV 1 The mean values for the two groups are shown in Table II. The bronchitics had a significantly lower mean FEV, than the patients without respiratory disease ( $P<0.01$, unpaired $t$ test), but there were no significant changes in $\mathrm{FEV}_{1}$ or $\mathrm{P}_{\bar{v}} \mathrm{CO}_{2}$, after placebo or either drug.

\section{T A B L E I I}

MEAN VALUES FOR FEV 1 (litres) AND Pv̄Co, (kPa)

\begin{tabular}{|c|c|c|c|c|c|c|c|}
\hline & \multirow{2}{*}{ Group } & \multicolumn{2}{|c|}{ Placebo } & \multicolumn{2}{|c|}{ Nitrazepam } & \multicolumn{2}{|c|}{ Flurazepam } \\
\hline & & Pre & Post & Pre & Post & Pre & Post \\
\hline $\mathrm{FEV}_{1}$ & $\begin{array}{l}\text { Bronchitic } \\
\text { Non-respiratory } \\
\text { All subjects }\end{array}$ & $\begin{array}{l}1 \cdot 48^{1} \\
2 \cdot 78 \\
2 \cdot 13\end{array}$ & $\begin{array}{l}1 \cdot 43^{1} \\
2 \cdot 81 \\
2 \cdot 12\end{array}$ & $\begin{array}{l}1 \cdot 43^{1} \\
2 \cdot 83 \\
2 \cdot 13\end{array}$ & $\begin{array}{l}1 \cdot 45^{1} \\
2 \cdot 86 \\
2 \cdot 15\end{array}$ & $\begin{array}{l}1 \cdot 49^{1} \\
2 \cdot 83 \\
2 \cdot 16\end{array}$ & $\begin{array}{l}1 \cdot 53^{1} \\
2 \cdot 82 \\
2 \cdot 17\end{array}$ \\
\hline $\mathrm{P}_{\overline{\mathrm{rCO}}}$ & $\begin{array}{l}\text { Bronchitic } \\
\text { Non-respiratory } \\
\text { All subjects }\end{array}$ & $\begin{array}{l}6 \cdot 96 \\
6 \cdot 43 \\
6 \cdot 69\end{array}$ & $\begin{array}{l}6 \cdot 45 \\
6 \cdot 43 \\
6 \cdot 44\end{array}$ & $\begin{array}{l}6 \cdot 03 \\
6 \cdot 27 \\
6 \cdot 15\end{array}$ & $\begin{array}{l}6 \cdot 19 \\
6 \cdot 35 \\
6 \cdot 27\end{array}$ & $\begin{array}{l}6 \cdot 84 \\
6 \cdot 03 \\
6 \cdot 43\end{array}$ & $\begin{array}{l}6 \cdot 80 \\
6 \cdot 18 \\
6 \cdot 55\end{array}$ \\
\hline
\end{tabular}

${ }^{1} \mathrm{FEV}_{1}$ for bronchitic group significantly less than for non-respiratory group $(P<0.01)$. No significant differences between pre- and post-drug values of $\mathrm{FEV}_{1}$ or $\mathrm{P}_{\mathbf{v}} \mathrm{CO}_{2}$ for either group or for the combined data on all subjects.

\section{DISCUSSION}

When benzodiazepines became available for clinical use they were thought not to depress respiration. The drugs were therefore considered safe for use in patients with respiratory failure. This view was supported when Matthew et al. (1969) reported 27 patients who had taken overdoses of nitrazepam with no evidence of respiratory depression. There was, however, only one chronic bronchitic among these patients. Rao et al. (1973) 
found slight depression of ventilation after diazepam but this was comparable to that occurring during normal sleep. Clark et al. (1971) reported three patients with acute on chronic respiratory failure in whom nitrazepam had apparently caused dangerous deterioration. This effect was confirmed by Pines (1972). All these patients deteriorated within hours of the drug being taken. In 1973 Model reported two further patients whose respiratory failure deteriorated following nitrazepam but only after the drug had been taken for nine days in one case and for 21 days in the other. It is not clear from this last report whether the drug was the sole factor responsible for the deterioration or whether an acute infection also played some part.

Gaddie et al. (1972) performed a double-blind cross-over trial to study the effect of nitrazepam, $10 \mathrm{mg}$, on patients with chronic respiratory failure in a stable state. There was no significant change in arterial tensions of oxygen or carbon dioxide but the $\mathrm{FEV}_{1}$ fell significantly at two hours after ingestion of the drug. This raised the possibility that the respiratory depression previously reported might be due to an effect on skeletal muscle rather than a direct suppression of the central drive to ventilation.

Similar results were obtained by Model and Berry (1974), who showed that regular oral chlordiazepoxide caused a significant fall in $\mathrm{FEV}_{1}$, associated with a rise in $\mathrm{P}_{\overline{\mathrm{V}} \mathrm{CO}_{2}}$, in patients with acute on chronic bronchitis.

The simplest way to assess the central drive to respiration is by measuring the ventilatory response to $\mathrm{CO}_{2}$. With this method ventilatory depression has been shown with opiates (Weil et al., 1975) and barbiturates (Gasser et al., 1975). There have been some previous studies of the effect of benzodiazepines on the ventilatory response, although none using nitrazepam or flurazepam. Sadove, Balagot, and McGrath (1965) demonstrated respiratory depression with pethidine which was not worsened by the simultaneous administration of intravenous chlordiazepoxide or diazepam. This was confirmed by Steen and his co-workers (Steen et al., 1966; Steen et al., 1967), who measured also the ventilatory response to $\mathrm{CO}_{2}$ after the administration of chlordiazepoxide and diazepam, both alone and with pethidine, in normal volunteers. No depression of $\mathrm{CO}_{2}$ sensitivity could be demonstrated with these benzodiazepines.

Using the rebreathing method of Read (1967) to assess ventilatory response to $\mathrm{CO}_{2}$, Cohen,
Finn, and Steen (1969) were unable to show anyo depression as a result of intravenous diazepamb in normal subjects, and there was even a sugen gestion that diazepam antagonized the respiratoryo depression induced by pethidine. More detailect studies were done by Catchlove and Kafer (1971), both in normal subjects and in patients with $\vec{P}$ chronic bronchitis after intravenous diazepam $\overrightarrow{\vec{A}}$ The $\mathrm{CO}_{2}$ sensitivity was reduced in some patient䓪 but unchanged and even increased in others There was no significant change for either grouk overall. Gasser et al. (1975) showed marked re $\vec{F}$ duction in ventilatory response to $\mathrm{CO}_{2}$ after pento barbitone and pentazocine but no significanto change after lorazepam.

The significant depression of $\mathrm{CO}_{2}$ sensitivity by flurazepam shown in our study is, to our know? ledge, the first unequivocal evidence of centraf depression of respiration by a benzodiazepine. The्ष lack of any change in $\mathrm{FEV}_{1}$ argues against the muscle relaxant properties of the drug being significant and implies true depression of centra drive. We were unable to demonstrate any signifi응 cant change after nitrazepam, which raises the possibility of different behaviour among the difo ferent drugs of this group. The doses given ar: approximately equal in hypnotic effect. Th\& failure of both this study with nitrazepam and the previous studies quoted above to demonstrate respiratory depression implies that such an effect cannot be very great. It may then be important. only in patients when an acute exacerbation of respiratory failure causes a deterioration i respiratory function such that any small change्र in central drive or muscular power becomes critical. This is supported by our observations. that in spite of a change in $\mathrm{CO}_{2}$ sensitivity there was no significant change in $\mathrm{P}_{\overline{\mathrm{C}} \mathrm{CO}_{2}}$.

Our results refer to the effects of a single dose of benzodiazepine, not to long-term administrab tion. We believe that the administration of sedatives or hypnotics to patients with acutes respiratory failure, or an acute excerbation of chronic respiratory disease, is always contras indicated. The position for patients with chronie stable respiratory failure and $\mathrm{CO}_{2}$ retention less certain, but we feel that the indication for sedatives, if prescribed, should be compelling, an the patient should be under close observation.

There is no good evidence that chronic bronchi tics with a normal arterial carbon dioxide tensio will come to harm after a single dose of a benzo? diazepine. However, should such a drug be pre scribed it would be reasonable to prefer 
nitrazepam to flurazepam in view of the results of this study.

We are grateful to Roche Products Ltd both for supplies of nitrazepam and flurazepam and for a generous grant towards equipment. During this work Dr. Rudolf held a Sir Jules Thorn Research Fellowship.

\section{REFERENCES}

Borland, R. G. and Nicholson, A. N. (1975). Comparison of the residual effects of two benzodiazepines (nitrazepam and flurazepam hydrochloride) and pentobarbitone sodium on human performance. British Journal of Clinical Pharmacology, 2, 9.

Campbell, E. J. M. and Howell, J. B. L. (1962). Rebreathing method for measurement of mixed venous $\mathrm{PCO}_{2}$. British Medical Journal, 2, 630.

Catchlove, R. F. H. and Kafer, E. R. (1971). The effects of diazepam on respiration in patients with obstructive pulmonary disease. Anesthesiology, 34, 14.

Clark, T. J. H., Collins, J. V., and Tong, D. (1971). Respiratory depression caused by nitrazepam in patients with respiratory failure. Lancet, 2, 737.

Cohen, R., Finn, H., and Steen, S. N. (1969). Effect of diazepam and meperidine, alone and in combination, on respiratory response to carbon dioxide. Anesthesia and Analgesia . . . Current Researches, 48, 353.

Gaddie, J., Legge, J. S., Palmer, K. N. V., Petrie, J. C., and Wood, R. A. (1972). Effect of nitrazepam in chronic obstructive bronchitis. British Medical Journal, 2, 688.

Gasser, J. C., Kaufman, R. D., and Bellville, J. W. (1975). Respiratory effects of lorazepam, pentobarbitol and pentazocine. Clinical Pharmacology and Therapeutics, 18, 170.

Matthew, H., Proudfoot, A. T., Aitken, R. C. B., Raeburn, J. A., and Wright, N. (1969). Nitrazepam-a safe hypnotic. British Medical Journal, $\mathbf{3}, 23$.
Medical Research Council (1965). Report. Definition and classification of chronic bronchitis for clinical and epidemiological purposes. Lancet, 1, 775.

Model, D. G. (1973). Nitrazepam induced respiratory depression in chronic obstructive lung disease. British Journal of Diseases of the Chest, 67, 128.

Model, D. G. and Berry, D. J. (1974). Effects of chlordiazepoxide in respiratory failure due to chronic bronchitis. Lancet, 2, 869.

Pines, A. (1972). Nitrazepam in chronic obstructive bronchitis (Letter). British Medical Journal, 3, 352.

Rao, S., Sherbaniuk, R., Prasad, K., Lee, S. J. K., and Sproule, B. J. (1973). Cardiopulmonary effects of diazepam. Clinical Pharmacology and Therapeutics, 14, 182.

Read, D. J. C. (1967). A clinical method for assessing the ventilatory response to carbon dioxide. Australasian Annals of Medicine, 16, 20.

Sadove, M. S., Balagot, R. C., and McGrath, J. M. (1965). Effects of chlordiazepoxide and diazepam on the influence of meperidine on the respiratory response to carbon dioxide. Journal of New Drugs, 5, 121.

Steen, S. N., Amaha, K., Weitzner, S. W., and Martinez, L. R. (1967). The effect of chlordiazepoxide and pethidine, alone and in combination, on the respiratory response to carbon dioxide. British Journal of Anaesthesia, 39, 374.

Steen, S. N., Weitzner, S. W., Amaha, K., and Martinez, L. R. (1966). The effect of diazepam on the respiratory response to carbon dioxide. Canadian Anaesthetists Society Journal, 13, 374.

Weil, J. V., McCullough, R. E., Kline, J. S., and Sodal, I. E. (1975). Diminished ventilatory response to hypoxia and hypercapnia after morphine in normal man. New England Journal of Medicine, 292, 1103.

Requests for reprints to: Dr. D. M. Geddes, Westminster Hospital, Dean Ryle Street, London SW1P 2AP. 